\title{
Progressive encephalopathy in a Crohn's disease patient on long-term total parenteral nutrition: possible relationship to selenium deficiency
}

\author{
Keishi Kawakubo, Mitsuo Iida, Takayuki Matsumoto, Yuichi Mochizuki, \\ Kosei Doi, Kunihiko Aoyagi and Masatoshi Fujishima
}

Second Department of Internal Medicine, Faculty of Medicine, Kyushu University, 3-1-1 Maidashi, Higashi-ku, Fukuoka City, Japan 812

\begin{abstract}
Summary: The case of a patient with Crohn's disease complicated by progressive and irreversible encephalopathy, who had been on long-term total parenteral nutrition due to short bowel syndrome, is described. He initially experienced a disturbance of his vision, which was followed by various neurological symptoms during the next 3 years. These symptoms rapidly progressed until he finally developed consciousness disturbance. He also manifested erythrocytic macrocytosis, a low serum level of tri-iodothyronine and a high level of thyroxine. His blood levels of various trace minerals and vitamins were normal, except for selenium, which showed extremely low values. In addition, impaired plasma glutathion peroxidase activity was confirmed. After intravenous supplementation of selenium, macrocytosis, tri-iodothyronine and thyroxine values, and glutathione peroxidase activity all became normalized, yet he improved little neurologically.

Our case suggests that long-term selenium deficiency may cause progressive and irreversible encephalopathy, and that careful monitoring of this mineral is necessary when an excessive period of total parenteral nutrition is being considered in the clinical setting.
\end{abstract}

\section{Introduction}

Selenium is a well-known trace mineral needed in humans and in animals. While at least 13 selenoproteins have been identified in animals, this mineral has been described as being an essential element of an enzyme glutathione peroxidase (GSH-Px) in humans. ${ }^{1}$ More recently, it has been reported that selenium deficiency causes impairment in conversion of L-thyroxine $\left(\mathrm{T}_{4}\right)$ into $3,3^{\prime}, 5$ tri-iodothyronine $\left(\mathrm{T}_{3}\right)$ in experimental animals. ${ }^{2,3}$

During the past two decades, many disease conditions induced by selenium deficiency have been reported in both humans and animals. These included cardiomyopathy, ${ }^{4-11}$ myopathy, ${ }^{12-21}$ macrocytosis, ${ }^{18}$ nail weakening, ${ }^{18}$ exudative diathesis ${ }^{22}$ and hepatic necrotic degeneration. ${ }^{23}$

We recently experienced a case of encephalopathy probably induced by long-term selenium deficiency. The detailed clinical course and laboratory data of the patient, including plasma GSH-Px activities, and serum $T_{3}$ and $T_{4}$ values are described and the possible importance of selenium in parenteral nutrition is discussed.

Correspondence: Keishi Kawakubo, M.D.

Accepted: 18 August 1993

\section{Case report}

A 38 year old male was admitted to our hospital for evaluation and treatment of progressive consciousness disturbance in August 1989.

At the age of 19, he was diagnosed as having Crohn's disease of the small intestine, which required surgical resection three times. Because this surgery had resulted in short bowel syndrome (the remaining small intestine measured $120 \mathrm{~cm}$ in length), he had been nutritionally managed by total parenteral nutrition (Table I) and oral elemental diet, which had included no selenium, since August 1982. After 4 years, during which elemental diet was his only oral intake, he gradually developed visual disturbances. Over the next 3 years, he manifested various neurological abnormalities, such as paraesthesiae, dysarthria and spasticity, as explained in Figure 1. These abnormalities rapidly exacerbated in July 1989 and he finally developed disordered consciousness.

Upon physical examination, his nails were weak with whitish nail beds. His posture was decortical, with exaggerated deep tendon reflexes and spasticity in the extremities. His consciousness level was 
similar to that of patients suffering from apallic syndrome (a state of unresponsiveness due to diffuse cortical or brainstem damage). External stimuli, such as sound and pain, caused his eyes to open, but he did not respond to verbal or written orders. He had day and night rhythm and gag reflexes, and while awake he moaned loudly.
Laboratory examinations showed macrocytosis (mean cell volume (MCV) $120 \mathrm{fl}$ ) with a normal haemoglobin concentration, but with an elevated serum creatine kinase (CK) level (492 IU/l; normal 60-160). No electrolyte imbalance was found. Neither hepatic nor renal failure was evident. His serum $T_{3}$ concentration was decreased $(0.4 \mathrm{ng} / \mathrm{ml}$;

Table I Parenteral nutrition solutions

\begin{tabular}{lclr}
\hline Total volume & $2,500 \mathrm{ml}$ & Vitamin A & $2,500 \mathrm{IU}$ \\
Glucose & $390 \mathrm{~g}$ & Vitamin $\mathbf{B}_{1}$ & $13.8 \mathrm{mg}$ \\
Aminoacid & $60 \mathrm{~g}$ & Vitamin $\mathbf{B}_{2}$ & $3.9 \mathrm{mg}$ \\
Lactate & $12 \mathrm{mEq}$ & Vitamin $\mathbf{B}_{6}$ & $2.4 \mathrm{mg}$ \\
Phosphate & $9 \mathrm{mEq}$ & Vitamin B $_{12}$ & $30 \mu \mathrm{g}$ \\
Acetate & $75 \mathrm{mEq}$ & Vitamin C & $1,100 \mathrm{mg}$ \\
Gluconate & $12 \mathrm{mEq}$ & Vitamin D & $200 \mathrm{IU}$ \\
Sodium & $70 \mathrm{mEq}$ & Vitamin E & $15.0 \mathrm{mg}$ \\
Potassium & $69 \mathrm{mEq}$ & Vitamin K & $2.0 \mathrm{mg}$ \\
Chloride & $70 \mathrm{mEq}$ & Folic acid & $1,000 \mu \mathrm{g}$ \\
Calcium & $12 \mathrm{mEq}$ & Nicotinic acid & $20.0 \mathrm{mg}$ \\
Magnesium & $9 \mathrm{mEq}$ & Biotin & $200 \mathrm{mg}$ \\
Phosphorus & $372 \mathrm{mEq}$ & Pantothenic acid & $12.0 \mathrm{mg}$ \\
Sulphate & $9 \mathrm{mEq}$ & Lipids (per week) & \\
Iron & $70 \mu \mathrm{mol}$ & Fractionated soya oil & $40 \mathrm{~g}$ \\
Zinc & $120 \mu \mathrm{mol}$ & Fractionated ovolecithin & $2.4 \mathrm{~g}$ \\
Iodine & $2 \mu \mathrm{mol}$ & Glycerin & $4.5 \mathrm{~g}$ \\
Copper & $10 \mu \mathrm{mol}$ & & \\
\hline
\end{tabular}

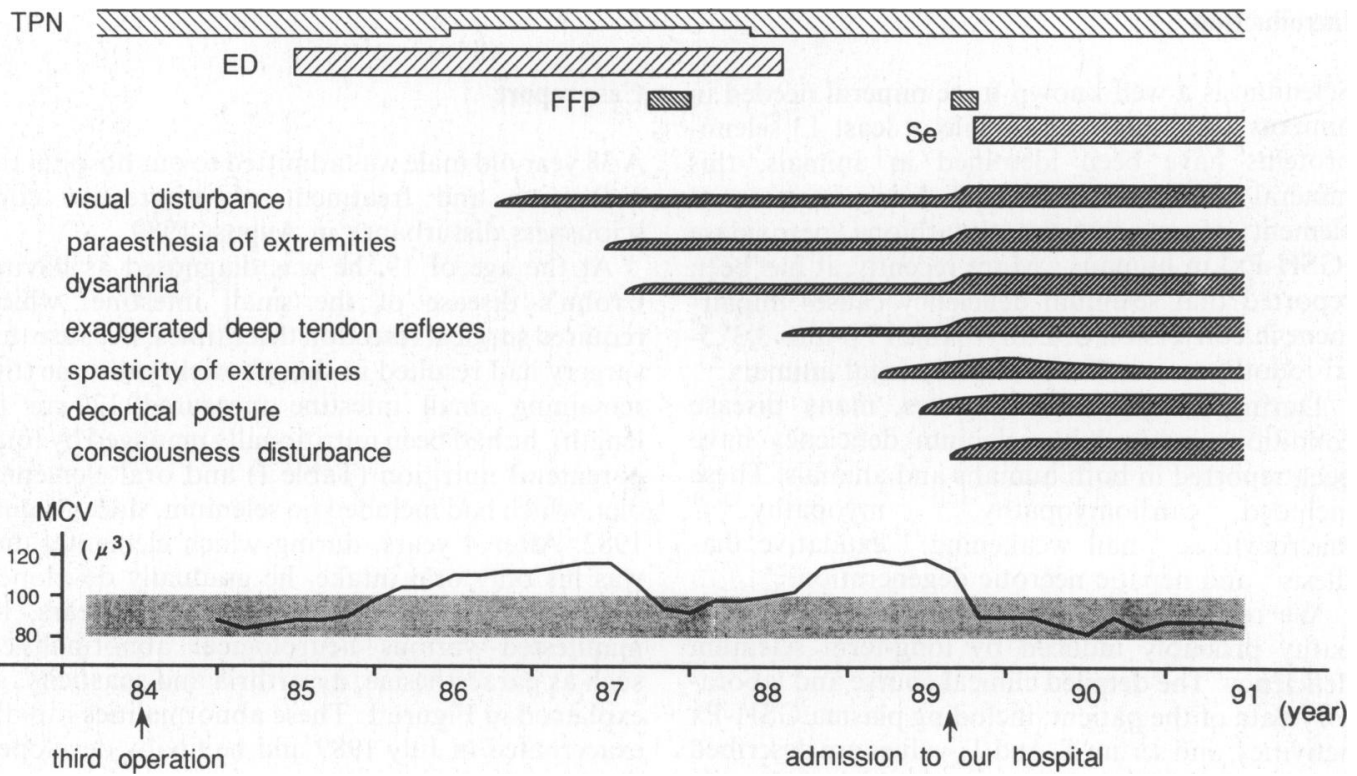

Figure 1 Clinical course of the patient. Dotted area indicates the normal range. Note the gradual increase in mean cellular volume (MCV) of erythrocytes according to the onset of neurological symptoms, and the quick response of MCV to frozen fresh plasma (FFP) and selenium (Se) administration. TPN = total parenteral nutrition; ED = elemental diet. 
normal $0.9-2.1$ ), the serum $T_{4}$ concentration was increased $(22.4 \mu \mathrm{g} / \mathrm{dl}$; normal $4.5-12.5)$, while the thyroid stimulating hormone was within the normal range $(1.35 \mu \mathrm{U} / \mathrm{ml}$; normal $0.2-4.7)$. The electroencephalogram was almost normal, whereas computed tomography showed marked brain atrophy without any localized abnormalities (Figure 2). Sural nerve and muscle biopsies revealed axonal degeneration and diffuse muscular atrophy.

Because hypovitaminosis and deficiency in trace minerals were strongly suggested by his clinical course, the serum values of these elements were further investigated. Whereas the levels of vitamin (A, B $, B_{2}, B_{6}, B_{12}, C, D$ and E), folic acid and most of the trace mineral concentrations (zinc, manganese, phosphorus, magnesium, copper, ferrum, chromium, iodine and aluminium) were higher than the lower limits, his blood selenium level was extremely low (3.6 $\mu \mathrm{g} / \mathrm{dl}$; normal 12.2-35.8) (Table II).

\section{Clinical course after admission}

We suspected a possible correlation between selenium deficiency and encephalopathy, and frozen fresh plasma (FFP) containing selenium was administered initially. Thereafter, he received pure intravenous sodium selenite $(200 \mu \mathrm{g} /$ day $)$.

In order to assess accurately the effect of administered selenium, both blood selenium concentration and plasma GSH-Px activity were simultaneously measured before and after treatment. While blood selenium concentration gradually increased, plasma GSH-Px activity, which had been low $(19 \mathrm{U} / \mathrm{L})$ before the treatment, rapidly recovered to $182 \mathrm{U} / \mathrm{L}$, and henceforth, it consistently showed normal values. In addition, $\mathrm{MCV}$, serum $\mathrm{T}_{3}$ and $\mathrm{T}_{4}$ values were all normalized. Although these parameters improved dramatically, the patient showed no apparent neurological improvement, except for a slight decrease in spasticity in his extremities and a normalization of his nail colour.

\section{Discussion}

Because selenium is found in the soil and is included in all kinds of food, a deficiency in this mineral rarely occurs in human or in animals,

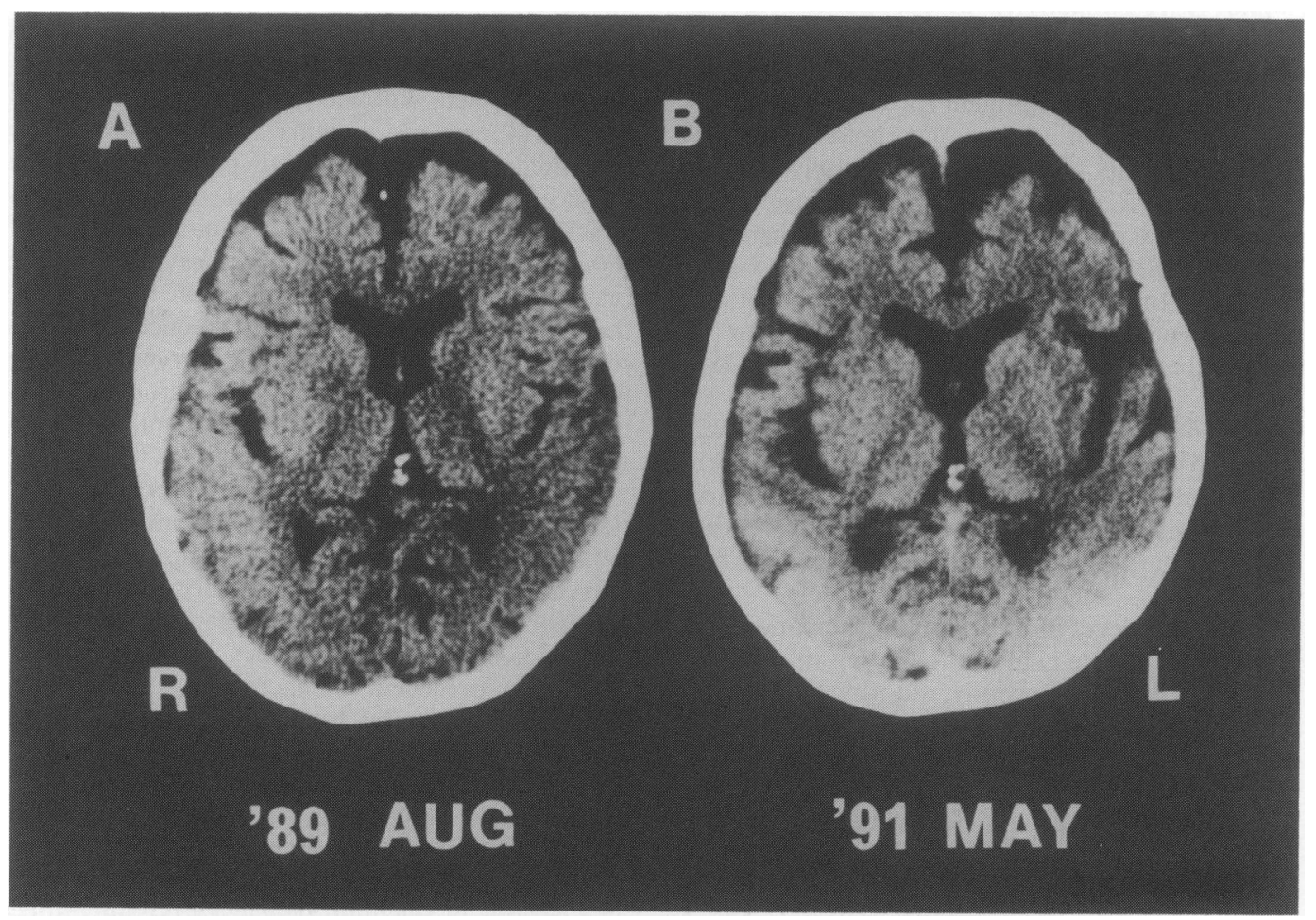

Figure 2 Serial changes in brain computed tomography of the patient. (A) Computed tomography on admission reveals that the cerebrum was markedly and diffusely atrophic without any localized abnormality. (B) 21 months later, the brain atrophy had further progressed. 
Table II Serum vitamin and trace mineral levels on admission to our hospital

\begin{tabular}{clll}
\hline Vitamins & & & \\
$\mathrm{A}$ & $581(410-1,200) \mathrm{ng} / \mathrm{ml}$ & Zinc & $130.1(70-140) \mu \mathrm{g} / \mathrm{dl}$ \\
$\mathrm{B}_{1}$ & $11.5(1.5-6.0) \mu \mathrm{g} / \mathrm{dl}$ & Manganese & $0.4(0.4-2.0) \mu \mathrm{g} / \mathrm{dl}$ \\
$\mathrm{B}_{2}$ & $27.7(6-10) \mu \mathrm{g} / \mathrm{dl}$ & Phosphorus & $4.6(2.6-4.3) \mathrm{mg} / \mathrm{dl}$ \\
$\mathrm{B}_{6}$ & $10.7(3.6-18) \mathrm{ng} / \mathrm{ml}$ & Magnesium & $1.9(1.8-2.6) \mathrm{mg} / \mathrm{dl}$ \\
$\mathrm{B}_{12}$ & $\geqslant 1,800(230-800) \mathrm{pg} / \mathrm{ml}$ & Copper & $130(78-131) \mu \mathrm{g} / \mathrm{dl}$ \\
$\mathrm{C}$ & $4.3(0.2-2.0) \mathrm{mg} / \mathrm{dl}$ & Iron & $59(54-200) \mu \mathrm{g} / \mathrm{dl}$ \\
$\mathrm{D}$ & $14.6(10-55) \mathrm{ng} / \mathrm{ml}$ & Chromium & $0.07(<1.0) \mu \mathrm{g} / \mathrm{dl}$ \\
$\mathrm{E}$ & $0.82(0.75-1.4) \mathrm{mg} / \mathrm{dl}$ & Selenium & $3.6(12.2-35.8) \mu \mathrm{g} / \mathrm{dl}$ \\
Folic acid & $7.4(2.3-6.5) \mathrm{ng} / \mathrm{ml}$ & Iodine & $13(4-9) \mu \mathrm{g} / \mathrm{dl}$ \\
& & Aluminium & $1.2(<0.76) \mu \mathrm{g} / \mathrm{dl}$
\end{tabular}

Normal ranges are given in parentheses.

except for some particular areas of the world, where the soil contains low levels of selenium. ${ }^{4,5}$ However, it has been recently demonstrated in several studies that iatrogenic selenium deficiency occurs in patients on long-term parenteral nutrition who did not receive selenium supplementation. ${ }^{6-18}$

It has been previously reported that total parenteral nutrition of 4-44 months' duration induces a decrease in blood selenium levels. ${ }^{6-18}$

The GSH-Px activity in the patient showed extraordinarily low values prior to selenium supplementation. Because selenium has been reported to be an essential component for GSH-Px activity, both in vitro and in vivo, the rapid increase in GSH-Px activity in our patient strongly suggests that the intravenously administered selenium actually possessed some biological effect. Furthermore, because GSH-Px is an important antioxidant, necessary for preventing the accumulation of lipid peroxide radicals, it can be speculated that the increased radicals induced by inactivation of GSHPx may have played an important role in the pathogenesis of systemic and irreversible damage, especially in the nervous system, of the patient. This speculation is further supported by previous work demonstrating intracellular mitochondrial injury induced by selenium deficiency in an experimental study. ${ }^{21}$

The serum level of $T_{3}$ and $T_{4}$ in the patient also showed noticeable changes following infusions of FFP and selenium. Recently, iodothyronine deiodinase, which is a key enzyme in the conversion of $\mathrm{T}_{4}$ to $T_{3}$, has been identified as one of the selenoproteins in an animal study. ${ }^{2,3}$ Thus the increased $\mathrm{T}_{4}$ and decreased $\mathrm{T}_{3}$ in the patient before treatment seem to have been derived from the impaired metabolism of thyroid hormones induced by selenium deficiency. The normalization of $T_{3}$ and $T_{4}$ following selenium administration further supports this speculation.

The clinical features of selenium deficiency des- cribed previously included cardiomyopathy, ${ }^{4-11}$ peripheral myopathy with elevated serum CK, 12-18 changes in nail colour ${ }^{18}$ and macrocytosis in erythrocytes. ${ }^{18}$ While all of these manifestations, except for cardiomyopathy, were found in our patient, the most characteristic feature of the patient was progressive encephalopathy, which has not been previously described in patients with selenium deficiency.

There may be an argument that the encephalopathy in our patient can be explained by vitamin deficiency which may occur in long-term parenteral nutrition, because deficiency in vitamin $E$ and $B_{12}$ has been well known to affect central and peripheral nervous systems in humans. ${ }^{24,25}$ The neurological features of our patient resembled those seen in patients with either vitamin $E$ or $B_{12}$ deficiencies but serum or blood concentration of these vitamins showed high values prior to the onset of neurological abnormalities. In addition, there was no other clinical evidence, such as ceroid-lipofuscin storage in the nerves, sea-blue histiocytes in bone marrow and macrocytic anaemia, which are characteristic of vitamin $E$ or $B_{12}$ deficiency.

The evidence which suggested the possible relation between the encephalopathy and selenium deficiency in our patient was that there was a close correlation between his encephalopathy and increase in MCV, which was considered to have been derived from selenium deficiency. His visual disturbance was preceded by macrocytosis and during the next 3 years he gradually developed consciousness disturbance as the MCV increased. Because the duration of selenium deficiency was much longer than those in the previous reports documenting selenium deficiency with no neurological abnormalities, it can be assumed that excessive periods of selenium deficiency possibly affect the nervous systems in humans adversely.

Although other unknown causes may have been partly related to the pathogenesis of encephalo- 
pathy in our patient, marked cerebral degeneration is observed in selenium-deficient chicks ${ }^{22}$ and dyscrasic encephalopathy. ${ }^{26}$ In as much as the patient did not improve dramatically following selenium administration, which normalized his blood selenium levels, his plasma GSH-Px activity, serum $\mathrm{T}_{3}$ and $T_{4}$ values, his macrocytosis, and his nail colour, brain damage arising from selenium deficiency can be considered to be irreversible. It would thus seem that it should become mandatory to routinely measure blood selenium concentrations in patients who are on oral elemental diet or parenteral

\section{References}

1. Rotruck, J.T., Pope, A.L., Ganther, H.E., Swanson, A.B., Hafeman, D.G. \& Hoekstra, W.G. Selenium: biochemical role as a component of glutathione peroxidase. Science 1973, 179: $588-590$.

2. Arthur, J.R., Nicol, F. \& Beckett, G.J. Hepatic iodothyronine $5 '$-deiodinase - the role of selenium. Biochem J 1990, 272: $537-540$.

3. Behne, D., Kyriakopoulos, A. \& Meinhold, H. Identification of type I iodothyronine $5^{\prime}$-deiodinase as a selenoenzyme. Biochem Biophys Res Commun 1990, 173: 1143-1149.

4. Keshan Disease Research Group of the Chinese Academy of Medical Sciences. Epidemiologic studies on the etiologic relationship of selenium and Keshan disease. Chin Med J 1979, 92: 477.

5. Thomson, C.D. \& Robinson, M.F. Selenium in human health and disease with emphasis on those aspects peculiar to New Zealand. Am J Clin Nutr 1980, 33: 303-323.

6. van Rij, A.M., Thomson, C.D., McKenzie, J.M. \& Robinson, M.F. Selenium deficiency in total parenteral nutrition. Am J Clin Nutr 1979, 32: 2076-2085.

7. Johnson, R.A., Baker, S.S., Fallon, J.T. et al. An accidental case of cardiomyopathy and selenium deficiency. $N$ Engl $J$ Med 1981, 304: 1210-1212.

8. Fleming, C.R., Lie, J.T., McCall, J.T., O’Brien, J.F., Baillie, E.E. \& Thistle, J.L. Selenium deficiency and fatal cardiomyopathy in a patient on home parenteral nutrition. Gastroenterology 1982, 83: 689-693.

9. Volk, D.M. \& Cutliff, S.A. Selenium deficiency and cardiomyopathy in a patient with cystic fibrosis. $\mathrm{J} \mathrm{Ky} \mathrm{Med} \mathrm{Assoc}$ 1986, 84: 222-224.

10. Sriram, K., Peterson, J.K., O’Gara, J. \& Hammond, J.M. Clinical improvement of congestive heart failure after selenium supplementation in total parenteral nutrition. Acta Pharmacol Toxicol (Copenh) 1986, 59 (Suppl 7): 361-367.

11. Matsusue, S., Kashihara, S. \& Tomonaga, G. Selenium deficiency and cardiomyopathy in a patient on long-term parenteral nutrition. Jpn $J$ Surg 1987, 88: 483-488.

12. Stanley, J.C., Alexander, J.P. \& Nesbitt, G.A. Selenium deficiency during total parenteral nutrition - A case report. Ulster Med J 1982, 51: 130-132.

13. Kien, C.L. \& Ganther, H.E. Manifestations of chronic selenium deficiency in a child receiving total parenteral nutrition. Am J Clin Nutr 1983, 37: 319-328.

14. Watson, R.D., Cannon, R.A., Kurland, G.S., Cox, K.L. \& Frates, R.C. Selenium responsive myositis during prolonged home total parenteral nutrition in cystic fibrosis. JPEN 1985, 9: $58-60$ nutrition for a long period. Moreover, it is important to add selenium as one of the necessary elements, along with other trace minerals such as zinc and copper, which are all clearly known to induce severe manifestations when they are absent, or in short supply in the diet.

\section{Acknowledgements}

We wish to thank Miss K. Miller (Royal English Language Centre) for proofreading the English used in this manuscript.

15. Selenium deficiency in a woman given total parenteral nutrition. Nutr Rev 1985, 43: 339-341.

16. Brown, M.R., Cohen, H.J., Lyons, J.M. et al. Proximal muscle weakness and selenium deficiency associated with long term parenteral nutrition. Am J Clin Nutr 1986, 43: 549-554.

17. Kelly, D.A., Coe, A.W., Shenkin, A., Lake, B.D. \& WalkerSmith, J.A. Symptomatic selenium deficiency in a child on home parenteral nutrition. J Pediatr Gastroenterol Nutr 1988, 7: 783-786.

18. Vinton, N.E., Dahlstrom, K.A., Strobel, C.T. \& Ament, M.E. Macrocytosis and pseudoalbinism: manifestations of selenium deficiency. J Pediatr 1987, 111: 711-717.

19. Muth, O.H., Oldfield, J.E. \& Schubert, J.R. White muscle disease (myopathy) in lambs and calves. VI. effects of selenium and vitamin E on lambs. Am J Vet Res 1959, 75: 231-233.

20. Burk, R.F. Selenium in nutrition. World Rev Nutr Diet 1978, 30: 88-106.

21. Whanger, P.D., Weswig, P.H., Schmits, J.A. \& Oldfield, J.E. Effects of selenium and vitamin $E$ on blood selenium levels, tissue glutathione peroxidase activities and white muscle disease in sheep fed purified or hay diet. $J$ Nutr 1977, 107: 1298-1307.

22. Noguchi, T., Cantor, A.H. \& Scott, M.L. Mode of action of selenium and vitamin $\mathrm{E}$ in prevention of exudative diathesis in chicks. J Nutr 1973, 103: 1502-1511.

23. Schwartz, K. \& Foltz, C.M. Selenium as an integral part of factor 3 against dietary necrotic liver degeneration. $\mathrm{J} \mathrm{Am}$ Chem Soc 1957, 79: 3292-3293.

24. Satya-Murti, S., Howard, L., Krohel, G. \& Wolf, B. The spectrum of neurologic disorder from vitamin E deficiency. Neurology 1986, 36: 917-921.

25. Diamond, I. Nutritional disorders of the nervous system. In: Wyngaarden, J.B., Smith, L.H., Jr. \& Bennet, J.C. (eds) Cecil Textbook of Medicine, 19th edn. W.B. Saunders, Philadelphia, 1992, pp. 2125-2128.

26. Pentschew, A. Introduction to intoxications. In: Minckler, J. (ed.) Pathology of the Nervous System, Vol. 2. McGraw-Hill, New York, 1971, pp. 1618-1638. 